\title{
MENINA TEM QUE SE TRANSFORMAR EM MENINO PARA JOGAR FUTEBOL?
}

Tadeu João Ribeiro Baptista* Renata Cetano Otesbelgue**

\section{RESUMO:}

Este trabalho pretende compreender se há necessidade de masculinização da jogadora de Futebol. Para isto, o estudo esboça algumas lutas femininas para o ingresso no Futebol, salientando o gênero e a construção da sexualidade das jogadoras. Este estudo de caráter qualitativo e descritivo foi realizado com jogadoras de futebol de duas equipes amadoras adultas da cidade de Goiânia. Mediante os dados apresentados ñinaliza-se o jogo e fecha-se a súmulaò deixando expectativas de que o preconceito, contra as mulheres que jogam Futebol seja repensado, mediante a apresentação do que é ser mulher e de todo processo vivenciado por elas, entendendo que na fala das jogadoras existem controvérsias sobre a necessidade de masculinização para que elas sejam reconhecidas no futebol.

Palavras-Chave: Mulher; Futebol; Cultura; Gênero.

\section{O JOGO VAI COMEÇAR}

As mulheres tem alcançado uma participação mais efetiva no mercado de trabalho, o que representa uma mudança de comportamento social, a custa de muitas lutas travadas pelo movimento feminista, o que possibilitou o alcance da escolaridade superior e o desenvolvimento da sua participação na economia, na política e na sociedade. Apesar disso, os cargos de autoridade e chefia são pouco exercidos por elas. Porém, a área social fica quase exclusivamente destinada às mulheres, o que leva a perceber que o homem domina as áreas de poder e a mulher fica destinada aos serviços sociais, educativos e de produção simbólica (BOURDIEU, 2002).

Assim, cabe ressaltar que todos os significativos movimentos próigualdade e relações de gênero existentes, tem ainda um quadro bastante

\footnotetext{
"Professor de Educação Física pela ESEFEGO, Doutor em Educação pela UFG.

** Professora de Educação Física pela ESEFFEGO/UEG.
} 
variado de estereótipos que impedem a ascensão plena da mulher no mundo do trabalho.

A legislação maior do Brasil traz:

Todos são iguais perante a lei, sem distinção de qualquer natureza, garantindo-se [...] a inviolabilidade do direito à vida, à liberdade, à igualdade, [...], nos termos seguintes:

I ï homens e mulheres são iguais em direitos e obrigações, nos termos desta Constituição (BRASIL, 2003, p. 5).

Apesar de tal prerrogativa a mulher ainda permeia tratamentos injustos e é alvo de comentários descabidos, desvelando o preconceito existente. Conforme Tilly (apud COSTA, 2005), a desigualdade categorial consiste na distribuição desequilibrada de atributos entre um conjunto de unidades sociais, tais como indivíduos, categorias, grupos ou, regiões; tais fenômenos são próprios das experiências coletivas e interações sociais. No Brasil, vivemos em uma segregação sexual, pois, as mulheres não têm usufruído proporcionalmente, dos mesmos benefícios que homens ao longo dos anos, (BRASIL, 2009). Apesar das mulheres terem índices de escolaridade mais elevados, o seu rendimento médio é inferior em todas as categorias em relação aos homens, contribuindo para a instauração da dominação masculina. No esporte as condições de preconceito não se mostram diferentes, principalmente no trato com o Futebol, o qual é visto nacionalmente como um espaço masculino. A mulher vem angariando seu espaço esta modalidade, tentando romper com o pensamento machista retratado nas primeiras décadas do século $X X$, como é demonstrado abaixo:

[...] technicamente as jogadoras de futebol ou as pugilistas que se tentou exhibir aqui e alli não apresentam interesse algum; serão sempre imitações imperfeitas. [...] $\mathrm{E}$ por isso trabalham para a corrupção do esporte, aliás, para o levantamento da moral geral. [...]. Talvez as mulheres comprehenderão logo que esta tentativa não é proveitosa nem para seu encanto nem mesmo para sua saúde. De outro lado, entretanto, não deixa de ser interessante que a mulher possa tomar parte, em proporção bem grande, nos prazeres esportivos do seu marido e que a mãe possa dirigir intelligentemente a educação physica dos seus filhos (COUBERTIN apud GOELLNER, 2005, p. 143).

Nesta perspectiva da relação de gênero dentro das práticas esportivas, é importante para o decorrer do texto, sendo necessário 
compreender o entendimento de gênero e sexualidade adotados. De acordo com Jesus (2012, p. 12):

\begin{abstract}
Gênero se refere a formas de se identificar e ser identificada como homem ou como mulher. Orientação sexual se refere à atração afetivossexual por alguém de algum/ns gênero/s. Uma dimensão não depende da outra, não há uma norma de orientação sexual em função do gênero das pessoas, assim, nem todo homem e mulher é maturalmenteòheterossexual. [...]

Tal qual as demais pessoas, uma pessoa trans pode ser bissexual, heterossexual ou homossexual, dependendo do gênero que adota e do gênero com relação ao qual se atrai afetivossexualmente: mulheres transexuais que se atraem por homens são heterossexuais, tal como seus parceiros; homens transexuais que se atraem por mulheres também o são.
\end{abstract}

A partir dessa assertiva, as relações de gênero se diferenciam da orientação afetiva e sexual, pois, a construção sexual da identidade (gênero) depende da identificação com os papeis assumidos e se estes condizem ou não com o seu sexo de nascimento. Do ponto de vista da orientação afetiva e sexual, esta já depende da maneira como os interesses afetivos e sexuais se direcionam e, assim, podem assumir características, heterossexuais, homossexuais, bissexuais ou transexuais.

Este estudo apresenta a História da mulher na sociedade ocidental capitalista, enfocando o poder masculino sobre a mesma, bem como perceber se o mesmo ainda vigora no século XXI.

Ainda serão discutidos a História do Futebol como espaço masculino e as lutas e conquistas para que ocorresse o ingresso da mulher nesta modalidade esportiva. Para além destas altercações busca-se ainda entender o papel influenciador da mídia neste processo, ora sensacionalista ora apoiador do Futebol Feminino.

Na busca de compreender tal aspecto são feitas análises acerca do corpo feminino. Investiga-se as características adotadas pelas mulheres para ter suas capacidades físicas equiparadas com a dos homens, visto que o Futebol no Brasil ainda é considerado um esporte masculino, portanto tentando entender o corpo como uma nuance a mais para compreender as relações de gênero estabelecidas neste esporte.

Por fim propõe-se discutir as associações realizadas pelas mulheres no meio futebolístico, adotando como as principais o gosto pelo Futebol, as 
relações de homossexualidade por parte de algumas e os vínculos de amizade, formados neste espaço como em qualquer outro, mediante as escolhas e vivências parecidas.

\section{RUMO AO ÓGOALô}

O presente trabalho tem como objetivo, identificar e discutir as variadas causas que levam a jogadora de Futebol a uma possível masculinização para poder oferecer mostras de suas habilidade e capacidade neste esporte no cenário social. Busca-se, portanto, compreender tal prerrogativa a partir da análise da participação da mulher no decorrer da história, principalmente na sociedade brasileira, mediante suas representações e conquistas, esboçando as lutas para o seu ingresso no Futebol, bem como, discutir as influências cultural e midiática sobre a formação estereotipada do corpo feminino no contexto desse esporte, salientando o gênero e a construção da sexualidade das jogadoras da modalidade, retratando as discussões da apologia do corpo feminino no Brasil, da visão de sexualidade nesse esporte e as dificuldades da mulher conquistar o espaço futebolístico, rompendo com a r̃dominação masculinaò(BOURDIEU, 2002, p. 1).

\section{AS TÁTICAS E PROCEDIMENTOS}

O estudo buscou analisar, do ponto de vista histórico, social e cultural, se a mulher que joga Futebol realmente se masculiniza e quais suas reais necessidades de adotar tal postura para poder se destacar na modalidade, a qual foi sendo constituída como área predominante masculina. $\mathrm{Na}$ intenção de compreender o problema proposto, realizou-se uma pesquisa descritiva em dois times de Futebol Feminino do município de Goiânia- GO, na categoria Adulta Amador, por possuírem treinamento sistematizado para possíveis competições, sendo o Goiânia Esporte Clube e o Aliança Futebol Clube. Para realizar a aplicação da pesquisa entrou-se em contato com os presidentes dos times, por meio de ligação telefônica, onde os mesmos permitiram que fosse efetuada a pesquisa. 
A técnica de coleta de dados foi o questionário com perguntas abertas, as quais devem ser respondidas por escrito e de forma livre, usando linguagem própria, pelos integrantes do grupo pesquisado e sem a interferência da aplicadora (LAKATOS; MARCONI, 2003). Destaca-se ainda que o instrumento foi elaborado especificamente para este estudo.

Para a aplicação do questionário, a pesquisadora foi até o local de treinamento das jogadoras sendo a Vila Olímpica do Goiânia Esporte Clube e a FAMA ï Fundação de Assistência ao Menor Aprendiz, onde ocorrem o treinos do Aliança. Ao chegar aos referidos locais a pesquisadora explicou às jogadoras do que se tratava a pesquisa e que as mesmas tinham a opção de responder ou não o questionário. Ressalta-se que dentre as jogadoras que se propuseram a participar, antes de responder aos questionários cada qual assinou um termo de consentimento livre e esclarecido.

Dentre as opções do questionário a primeira questão colocada foi que as pesquisadas se intitulassem com um codinome, o qual acompanhará as informações disponibilizadas pelas mesmas, pois aqui se preferiu entender que os sujeitos são seres atuantes na sociedade.

Os dados levantados foram discutidos de forma qualitativa, através do método de análise de conteúdo. Conforme Bardin apud Triviños (1987) essa apreciação é um conjunto de formas de análise das comunicações, as quais através de procedimentos sistemáticos e objetivos de descrição visam compreender a mensagem do conteúdo, ou seja, pré-analisa, descreve e faz uma análise apoiada na interpretação referencial.

\section{O MEIO DE CAMPO: DIÁLOGOS TEÓRICO/EMPÍRICOS}

A história da mulher é predominantemente uma narrativa de controle e domínio da mulher pelo homem, sendo comum, a transferência de obediência do pai para o marido, e este fato vai dos tempos mais remotos até a existência do capitalismo, inclusive no Brasil (MARY DEL PRIORE, 2006). O Capitalismo tira a mulher do ambiente doméstico e a põe na fábrica sem condições dignas de trabalho, sendo considerada mão de obra barata, com salários inferiores aos dos homens, eclodindo movimentos grevistas femininos, destacando o dia 
oito de março de 1857, quando 129 mulheres foram incendiadas a mando dos patrões oficializando o conhecido r̃dia das mulheresò(COSTA, 2005).

Devagar os espaços sociais considerados masculinos passam a ter uma maior atuação das mulheres, como é o caso do Futebol. As primeiras partidas de Futebol feminino no Brasil ocorreram em 1913, entre os times dos bairros da Cantareira e do Tremembé, de São Paulo. Entretanto, a divulgação do jogo no outro dia, conforme Moura (2003) revelou que não houve a participação das mulheres como jogadoras e sim como organizadoras, visto que a ideia partiu das mesmas. Na verdade o que ocorreu no jogo foi que a metade dos rapazes do time do Americano vestiram trajes femininos para jogar. O jogo se destacou devido à figura de mulheres da elite realizar a ação, pois havia papéis sociais que as mesmas deveriam exercer, demonstrando uma participação feminina cada vez mais ativa no Brasil.

As mulheres operárias participavam das lutas pela diminuição da jornada de trabalho para 48 horas semanais, pelo direito à licença maternidade, pela formação de creches para os filhos e pela instrução generalista. As pertencentes à elite lutavam pela legalização do voto feminino, por meio da Legião da Mulher Brasileira. Os ideais, conforme a classe de cada mulher se divergia, pois as operárias consideravam a luta política importante, no entanto buscavam uma emancipação total e plena da sociedade patriarcal.

A produção Capitalista levou a mulher a atuar nos diversos espaços públicos, porém no meio futebolístico esta ficava apenas na torcida, o que mostra a nota:

Merece registro especial à ocorrência selecta e numerosa que aflui ao campo que apesar de não offerecer ainda as commodidades do fluminense, achava-se repleta de gentis senhoritas que são a alma dos jogadores, enthusiasmando-os com as suas palmas e vivas. (GAZETA DE NOTÍCIAS apud MOURA, 2003, p. 19).

A assistência feminina aos clubes ganhou tamanha importância que passaram a ocorrer concursos de madrinhas destes. Assim nasce a visão de que as mulheres executam o papel de auxiliares dos homens no Futebol, torcendo por um time determinado pelo pai, irmão ou namorado.

O eugenismo presente no Brasil naquele momento considerava a mulher burguesa como importante instrumento na formação do novo homem 
brasileiro, sendo esta livre de doenças e micróbios, praticante de exercícios para oferecer uma geração sadia e robusta à sociedade dominante. As práticas físicas femininas estavam ligadas a esportes como a Natação e a Dança que não tornariam rígidos seus gestos delicados e submissos. Conforme Bourdieu (2002) a sociedade exige que a mulher sempre sorria, baixe os olhos, mantenha as pernas juntas e as costas retas para representar sua devida docilidade. Apesar do direcionamento das práticas esportivas femininas, em 1921 ocorreu uma partida efetivamente jogada por mulheres, conforme a nota:

Teremos hoje, em Tremembé Tramway da Cantareira, um interessante jogo. É o seguinte: SHENHORITAS TREMEMBENSES $X$ SHENHORITAS CANTAREIRENSES ï Em prosseguimento as festas em honra a $\mathrm{S}$. Pedro, realiza-se hoje, às 15 horas, no campo do Tremembé F. C. um interessantíssimo jogo de Futebol entre dois quadros femininos. Os quadros obedecerão a seguinte organização: (Vermelho) Margot, Lili e Zélia, Rosa, Zica e Dalila; Jo (ilegível), Fany, Ruth, Mariazinha e Quiteria. (Verde) Marieta, Pequena e Lourdes, Cornélia, Norma e Zezé, Bellinha, Fernanda, Tita, Nêne e Consuelo. (MOURA, 2003, p.26).

O jogo foi o início do futebol como esporte feminino a partir da década de 1930. Porém, o mesmo era caricaturado, sendo visto pela sociedade e pela mídia como uma espécie de comédia, elencado na reportagem:

\footnotetext{
Realizou-se ante-hontem no campo do Brasil F. Clubb, na Piedade um jogo de football feminino entre as equipes r̂adame Lessa Alvesò e Madame Macedo [...].

A partida estava sendo disputada com enthusiasmo. As pequenas empregaram-se com extraordinário ardor. De vez em quando, uma acertava a bola ou esta batia nellas, de maneira a fazer vibrar a assistência [...].

Daqui há pouco a impetuosa f̃orwardòCélia, em violenta entrada, foi charqueada por Odette.

Foi a conta! A victima levantou-se e rãccertouòum bofetão em Odette. Ahi é que o tempo ñechouò mesmo de facto. As jogadoras se engalfinharam e o jogo foi suspenso [...]. Houve interrupção do jogo que prosseguiu depois, calmamente, finalizando com a victoria do team r̃essa Alvesò por 1 ï 0 . No final os assistentes carregaram as jogadoras [...] (JORNAL DOS SPORTS, 19/05/1931 apud MOURÃO; MOREL, 2005, p. 76).
}

A modalidade como esporte feminino seguiu uma teatralização até 1940, quando a eugenia no Estado Novo, através dos médicos, começou a condenar tal prática, sendo justificado por discursos como o do doutor 
Humberto Ballariny, que considerava essa atividade como naturalmente violenta, sendo um exacerbador do espírito combativo e da agressividade, qualidades incompatíveis com a mulher (MOURA, 2003).

A imprensa também buscava combater a prática do Futebol Feminino através de notas que demonstravam a sua incoerência com o temperamento e caráter feminino. Os jornais abordavam notas e artigos que tratavam do Futebol Feminino como um discurso médico impregnado pelo Dr. Leite Castro, como pode ser visto nesse artigo:

Como diversão, novidade e alegria dos đansôsequiosos por emoções differentes, póde ser tolerado o football praticado pelo sexo frágil, mas dentro dos princípios de educação physica e pelo lado estético e biológico é contraindicado [...]. Para a mulher, existem outras praticas, verdadeiramente sportivas, como a gymnastica e principalmente a natação, incapazes de trazer os distúrbios e as más conseqüências [...]. A lei porá então embargos à pratica prejudicial, ao organismo, à graça, e a belleza da mulher. (O Imparcial 08/05/1940 apud MOURA, 2003, p. 39).

A imprensa passa assim a disseminar a ideia de que o Futebol prejudicava a saúde, e a estética feminina, não condizendo a sua prática com o r̃sexo frágilò induzindo, desta maneira, os dirigentes de organizações a repensar o possível apoio às partidas de Futebol Feminino.

Devido ao interesse do governo Vargas de tratar o esporte como meio de educação moral, elevação cívica e aperfeiçoamento da raça, em 1941 é criada a legislação Esportiva que trazia normas para o desenvolvimento das práticas físico-esportivas femininas e proibia o Futebol enquanto modalidade para elas. De acordo com Moura (2003) a Subdivisão de Medicina Especializada pediu que fosse feita uma propaganda mostrando os males da prática do Futebol para as mulheres.

O jornal dos Sports era um dos poucos que se opunha à proibição do Futebol Feminino, realizando entrevistas com as jogadoras as quais indagavam as causas das mesmas não poderem jogar Futebol, o que causou certa inquietação social deixando a dúvida se a modalidade esportiva era ou não r̃coisa para mulherò(MOURA, 2003).

Do outro lado, o periódico O Imparcial divulgou uma entrevista com o Dr. Leite Castro que utilizou de um discurso eugênico apontando que a mulher 
estava destinada à leveza, harmonia das formas e a reprodução, o que pode ser evidenciado no seguinte recorte:

[...] Não é no foot-ball que a juventude feminina se aperfeiçoará. Pelo contrário $\ddot{i}$ é o foot-ball o sport que lhe trará defeitos e vícios, alterações geraes para a própria physiologia delicada da mulher, além de outras consequências de ordem traumática, podemos comprometter seriamente os órgãos da reprodução (ovário e útero). Si alguma autoridade me assistisse, faria daqui um appelo sincero a essa juventude feminina que se encontra iludida com phantasias do sport betão, para que abandone de vez o foot-ball, orientando-se para outros sectores educação physica [...] (O Imparcial, 19/06/1940, p. 8 apud MOURA,2003,pp. 45-46).

Em 1941, a professora Ana Cauduro divulgou um artigo na revista Nida e Saúdeò demonstrando a importância da participação da mulher na atividade física, porém estas deveriam prepará-la para ser mãe e gerar homens fortes e saudáveis, não considerando esta possibilidade no Futebol. Assim, percebe-se que o discurso eugênico, além de condenar o Futebol Feminino, pois considerava que as suas praticantes eram feias, mal cheirosas e brutalizadas, não era proferido apenas pelos homens (MOURA, 2003).

Após a proibição do Futebol Feminino em 1965 pelo Conselho Nacional de Desportos (CND), esta prática retorna nos anos de 1970 devido à retomada do movimento feminista brasileiro que passou a lutar pela legalização do aborto e do divórcio, construção de creches para as crianças das trabalhadoras, equidade salarial, a não violência contra a mulher e outros. Em 1976 ocorreu uma CPI da mulher no Congresso Nacional e, Maria Lenk, sendo a primeira mulher a disputar uma olimpíada na Natação, recomendou que fosse eliminada a proibição da prática do Futebol Feminino (MOURA, 2003).

No seu depoimento Lenk dizia: ñAcentuo bem o Futebol, porque atribuo a essa proibição, a quase impossibilidade do desenvolvimento do esporte feminino no Brasil [...]ò(MOURA, 2003, p. 56). Em 1979, o CND baixou uma deliberação que assegurava às mulheres brasileiras o direito à prática do Futebol. Porém, em 1980 a revista Placar publicava a seguinte reportagem:

Salve as tricoletes. No Arrudão elas fazem sucesso[...]: Depois da linha burra, da linha média e do ataque em linha, o tricolor do Recife lançou a linha đonita e gostosaô[...] Prova definitiva que futebol e mulher se dão bem (REVISTA PLACAR, 16/05/1980: 34 apud MOURA, 2003, p. 56). 
Para a mídia, a mulher além de ñser a mãe que lava o uniforme, a irmã que limpa as chuteiras, a namorada que serve bebidasò (DAOLIO, 2005, p. 140) para o homem, passou a ser objeto de sedução no imaginário futebolístico, não sendo admirada por suas técnica e tática e sim por suas curvas estereotipadas.

A mídia, na perspectiva do Futebol Feminino pode ser entendida como q́...] uma complexa teia de circulação, recepção e interação de informaçõesò (MOURÃO; MOREL, 2005, p.78) sendo influenciada e influenciando pelo viés cultural podendo refletir fenômenos sociais, ou seja, em certos momentos é instrumento de reconhecimento da mulher no meio Futebol, outrora a deprecia se pautando na fragilidade e no estereótipo corporal. Assim, é possível aproximar estas informações teóricas, dos dados identificados empiricamente.

Essa visão também é concebida pelas jogadoras deste estudo, onde algumas entendem a mídia como canal depreciador do referido esporte dizendo que ó Futebol feminino não tem investimento dos jornais, televisão [...] porque ele não tem boa estrutura no Brasilô (LADY, 2011), ou ainda, elas afirmam que ocasionalmente q́...] sai uma pequena notinha no jornais, enquanto no masculino sai na primeira página [...]ô (CEZINHA, 2011). Outras compreendem a mídia como importante instrumento para seu ingresso no Futebol: ócomecei a jogar Futebol desde pequena e o que me inspirou a jogar foi ver a Marta através da televisãoô(I.C., 2011).

Segundo Alvin (2008), as notícias sobre a participação da mulher no Futebol destacam geralmente a exaltação da beleza física da atleta em detrimento do seu talento esportivo, visto que consideram assim a notícia é mais fácil de vender, pois, o interesse da mídia atualmente é fazer com que este esporte e os seus partícipes se tornem uma mercadoria. Assim a transformação do Futebol em negócio, justifica o interesse cada vez maior da mídia na cobertura dos jogos femininos buscando se aproximar de fatias do público futebolístico (ALVIN, 2008). Portanto, se as curvas das jogadoras o que interessa, que elas sejam mostradas. O discurso sobre a corporalidade estigmatiza o Futebol Feminino, oprimindo a mulher e reafirmando funções diferenciadas para os gêneros. Destarte, o Futebol foi sendo afirmado como um 
espaço masculino, por isso, os homens tendem a opor às tentativas das mulheres em participar do mesmo.

A partir da ideia do Futebol como espaço masculino, tem ocorrido a adoção de certas características pelas mulheres que buscam jogá-lo de maneira sistematizada, ou seja, possuem time formado, técnico, treinos semanais com horários e dias determinados e participação de competições. A prática intensiva do Futebol por parte da mulher gera transformações em seu corpo. Desta maneira, Bourdieu (2002) aponta que ocorre uma desconstituição da ideia do corpo da mulher voltado para agradar a percepção dos homens, tendo capacidade de seduzi-los e prender a atenção dos mesmos.

Para Bourdieu (2002), além da análise estética esse público vem também adotando um novo padrão corporal, como forma de protesto contra a simbologia dominante, pois para afirmar a virilidade o homem executa uma postura ereta, com olhar para frente para que afirmem a masculinidade. Podese então nesta perspectiva traçar um percurso contrário, onde a mulher passa a adotar os gestos masculinos para apossar-se do poder atribuído aos homens.

As jogadoras de Futebol então, como aponta Silveira (2008), aumentam sua massa muscular, cortam os cabelos, buscam ser mais competitivas, ágeis e fortes, passam a imitar os gestos masculinos, como por exemplo, na locomoção, com as coxas mais afastadas uma das outras, assim redecoram a situação para poder jogar Futebol.

Ressalta-se, porém, que este posicionamento foi negado por algumas jogadoras pesquisadas as quais afirmaram que óNão é o esporte [...] que masculiniza, isso é uma opção da mulherô(PALUZY, 2011).

Outras jogadoras, porém, concordam que o corpo se masculiniza, mas, a essência continua sendo feminina ao dizerem que ño Futebol masculiniza pelo excesso de músculo, quando se há disposição genética, mas não psicologicamente, tem que haver mais que músculos para masculinizar totalmente uma mulherô (RANNY, 2011.) E existiu dentre as pesquisadas aquelas que concordam com Silveira (2008) onde afirmaram que óO Futebol masculiniza sim, até porque o Futebol Feminino não é valorizado, [...]ô (CEZINHA, 2011).

É perceptível, portanto, que uma possível masculinização das jogadoras de Futebol ainda é palco de divergências apresentadas pelos 
posicionamentos das pesquisadas. Porém, destaca-se que ao tomarem como suas as características masculinizadas, as mulheres voltam a serem vítimas do preconceito social, pois passam a ser rotuladas a partir desse âmbito como m̃machõesò porque para Bourdieu (2003), as mulheres passam a ser vistas pelos homens como não femininas ou até mesmo como homoafetivas, apesar de o Futebol, não poder ser rotulado como um r̃gueto gayò Os times de Futebol são sustentados, por três elementos principais: o gosto pela prática do esporte, às relações de homossexualidade e amizades formadas nesse meio (SILVEIRA, 2008).

Outro fator determinante na escolha das mulheres pela prática do Futebol é terem jogado esta modalidade boa parte da infância e adolescência com os meninos de suas respectivas ruas e/ou bairros por sentir prazer ao jogar, assim, quando adultas continuaram a ter interesse de forma sistematizada, desta maneira continua a treinar, armar jogada, disputar torneios e campeonatos, adquirir títulos, entre outros (SILVEIRA, 2008).

As ideias de Silveira (2008), neste sentido coadunam com esta pesquisa, pois, ao serem indagadas sobre quando iniciaram a jogar Futebol, as respostas foram: óComecei a jogar desde meus cinco anos de idade com meu irmão e nossos colegasô(DANY).

O gosto pelo Futebol, como apresentado, não é considerado pelas estudiosas do Futebol Feminino como Dornelles (2004) e Silveira (2008) como um fator de influência da sexualidade das mulheres. Nesta nuance tanto as heteroafetivas como as homoafetivas podem gostar e praticar este esporte.

Apesar de no meio futebolístico feminino existir a presença significativa de homoafetivas, Dornelles (2004) elenca que este espaço não pode ser determinado como um gueto gay, pois ele também tem 0 comparecimento de heterossexuais. Este aspecto foi reafirmado pelas pesquisadas as quais comentaram: óSer lésbica e jogar Futebol são duas coisas totalmente diferentes, [...]ô(DANY, 2011). Destarte, é preciso ficar claro que nem toda jogadora de Futebol é homossexual, por optar por um esporte considerado no Brasil como masculino e, mesmo que seja, ela precisa ser olhada para além da sua sexualidade enquanto pessoa.

A rotulação do Futebol Feminino como um espaço homoafetivo, conforme Silveira (2008) acarreta ainda em falta de patrocínios e incentivos ao 
desenvolvimento do esporte no país, devido ao preconceito estabelecido pela sociedade. Assim:

A forma dos preconceitos contra os/as homossexuais, gays e lésbicas, mais difícil de destruir é a criação de imagens globais, como se a homossexualidade definisse um modelo absoluto de personalidade e de ação, idéia que ninguém ousa aplicar aos heterossexuais (TOURAINE apud SILVEIRA, 2008, p.105).

É preciso romper com as barreiras preconceituosas e compreender que os praticantes, para além da sexualidade, partilham de um princípio em comum, que é gostar de Futebol, demonstrado pelas jogadoras dos times goianos quando indagadas sobre o porque da escolha desta modalidade esportiva que ó Futebol estava ligado em mim e me mostrou o que eu realmente queria serô(NATH, 2011), o que pode propiciar o estabelecimento de relações afins como a amizade.

Devido ao estabelecimento da convivência nos treinos, ocorre muitas vezes o estabelecimento de uma teia de amizades entre as integrantes e, desta forma, elas passam a frequentar espaços sociais de lazer também juntas, se inteirando dos assuntos e cotidianos umas das outras, como foi destacado por algumas das pesquisadas: óNos reunimos várias vezes em reuniões de família e até para fazer ação voluntária ajudando pessoas carentesô(RUBI, 2011).

Deste modo, o time de Futebol Feminino estabelece para além do que o nome propõe, forma um gosto em comum, um espaço em que pode ocorrer relacionamentos amorosos, homoafetivos ou não, e o estabelecimento de amizades sinceras presentes na vida nos mais variados momentos. Portanto, precisa-se rever o olhar preconceituoso sobre este esporte na sociedade brasileira.

\section{TERMINANDO O JOGO E FECHANDO A SÚMULA.}

As mulheres ao longo do processo histórico no ocidente foram colocadas socialmente como submissas aos homens, estando destinadas a cumprirem inicialmente as ordens do pai e depois a do marido, tendo como principais funções cuidar dos filhos e do lar, isto é, estava destinada a casar e procriar. 
$\mathrm{Na}$ sociedade ocidental e falocêntrica, para que as mulheres conseguissem superar a ideia imposta de serem apenas esposas e mães, foram necessárias diversas lutas. Assim, na perspectiva de conquistar a igualdade entre os gêneros, muitas mulheres se impuseram como homens, ou seja, passaram a se masculinizar, visto que as atividades femininas ficam sempre comparadas à referência masculina, como é o caso do Futebol Feminino brasileiro.

O Futebol até os anos de 1920 era visto como um espaço exclusivo de afirmação da masculinidade, por isso os homens tendem a opor as tentativas das mulheres em participar do esporte, para além do que eles consideram que a prática do esporte deforma o corpo feminino, visto que é imposto sobre ao universo femíneo um padrão de beleza a ser seguido para que desperte o desejo masculino, o que Bourdieu (2002) chamou de violência simbólica sobre as mulheres, ou seja, implicitamente, ainda lhes é imposta a função de casar, reproduzir e cuidar dos filhos.

A mídia pode ser considerada um veículo poderoso nesta formação estereotipada da mulher, fato que não foge à regra no Futebol Feminino, pois, os meios de comunicação divulgam pouco esta modalidade esportiva e muitas vezes pautam as transmissões por fatores estéticos das jogadoras e não a sua capacidade técnica e tática de jogar.

Mediante todas as interjeições apresentadas finaliza-se o jogo deixando expectativas de que o preconceito, o qual pode ser definido como q́...] uma antipatia baseada numa generalização errada e inflexível, que pode ser só sentida ou abertamente expressa e que pode ser dirigida a um grupo como um todo ou a um indivíduo por ser membro de um grupò̀ (ALLPORT apud COSTA, 2005, p. 45).

Todavia, os dados demonstram-se como contraditórios, uma vez que, algumas das atletas pesquisadas entendem a masculinização como natural, enquanto, outras não. Assim, entende-se que serão necessários novos estudos sobre o tema. 


\section{REFERÊNCIAS:}

ALVIN, Bianca. O papel da mídia na construção das identidades futebolísticas contemporâneas. XXXI Congresso Brasileiro de Ciência da Comunicação, 2008. Natal. Anais... Juiz de Fora: UFJF, 2008, p. 1 ï 10.

BOURDIEU, Pierre. A dominação masculina. Tradução de Maria Helena Kühner. 2. ed. Rio de Janeiro: Bertrande Brasil, 2002.

BRASIL. Constituição da República Federativa do Brasil: promulgada em 5 de outubro de 1988. 31. ed. São Paulo: Saraiva, 2003.

BRASIL. Ministério do planejamento, orçamento e gestão. Instituto Brasileiro de Geografia e Estatística. Brasília: 2009. Disponível em: http://www.ibge.gov.br/home/presidencia/noticias/noticia visualiza.php?id notic ia=1476\&id pagina=1. Acesso em: 21/11/2009.

COSTA, Eliana C. I. da. As novas formas de discriminação sexista: uma perspectiva da Psicologia Social. Tese (Doutorado em Educação). Campinas: UNICAMP, 2005.

COTRIM, Gilberto. História global: Brasil e geral. São Paulo: Saraiva, 1997.

DAÓLIO, Jocimar. A superstição no futebol brasileiro. In: DAÓLIO, Jocimar (Org.). Futebol, cultura e sociedade. Campinas: Autores Associados, 2005, p. 3-19.

DEL PRIORE, Mary. História das mulheres no Brasil. São Paulo: Contexto, 2006.

DORNELLES, Priscilla G. O Futebol feminino de várzea: uma análise cultural. Monografia de Especialização (Pedagogias do Corpo e da Saúde). Porto Alegre: UFRGS, 2004.

GOELLNER, Silvana V. Mulheres e futebol no Brasil: entre sombras e visibilidades. In: Revista de Educação e Esporte. São Paulo, v. 19, n. 2, p. 143151, 2005.

JESUS, Jaqueline G. Orientações sobre identidade de gênero: conceitos e termos. Guia técnico sobre pessoas transexuais, travestis e demais transgêneros, para formadores de opinião. 2. ed. Brasília, 2012. [e-book].

MACEDO, José R. A mulher na idade média. São Paulo. Editora Contexto. 1990. Disponível em: http://www.coladaweb.com/historia/a-mulher-na-idademedia. Acesso em: 23/07/2010.

LAKATOS, Eva M; MARCONI, Marina de A. Fundamentos da metodologia da pesquisa. 5. ed. São Paulo: Atlas, 2003.

MARQUES, Adhemar. Pelos caminhos da História. Curitiba: Ed. Positivo, 2006. 
MOURA, Eriberto J. L. As relações entre lazer, futebol e gênero. Dissertação (Mestrado em Educação Física). Campinas: UNICAMP, 2003.

MOURÃO, Ludmila; MOREL, Márcia. As narrativas sobre o futebol feminino: o discurso da mídia impressa em campo. In: Revista Brasileira de Ciências do Esporte. Campinas, v. 26, n. 2, p. 73-86, jan. 2005.

SILVEIRA, Raquel da. Esporte, homossexualidade e amizade: estudo etnográfico sobre o associativismo no futsal feminino. Dissertação (Mestrado em Ciências do Movimento Humano). Porto Alegre: UFRGS, 2008.

TRIVIÑOS, Augusto N. S. Introdução à pesquisa em Ciências Sociais: a pesquisa qualitativa em educação. São Paulo: Atlas S.A. 1987.

\title{
GIRLS HAVE TO BECOME MEN TO PLAY SOCCER?
}

\begin{abstract}
:
This research aims to understand if women who play soccer need to masculinize. For this, the study outlines some female fights to be admitted into soccer, emphasizing the gender and sexuality construction of female players. This qualitative and descriptive study was realized with athletes of two adult amateur teams of Goiania. Trough data presented r̃the game is over and the docket is closedò leaving expectations that prejudice against female soccer players is reconsidered upon the presentation of being a woman and all experienced process by the female soccer players, understanding that theirs speech there are controversies about the masculinization, so that they are recognized in soccer games.
\end{abstract}

Keywords: Women, Soccer, Culture and Gender.

\section{CHICA TIENE PARA TRANSFORMAR EN CHICO PARA JUGAR FUTBOL?}

\section{RESUMEN:}

Este trabajo pretende conocer si existe la necesidad de masculinización del jugador de fútbol. Para ello, el estudio se describen algunas de las peleas femeninas para la entrada en fútbol, haciendo hincapié en el género y la sexualidad de la construcción de los jugadores. Este estudio cualitativo y descriptivos se llevó a cabo con los jugadores de fútbol de dos equipos adulto aficionado de Goiânia. A través de los datos que se presentan "termina el juego y cierra el acta", dejando a las expectativas de que el prejuicio contra las mujeres juegan al fútbol se reconsidera la presentación de ser mujer y todo el proceso vivido por ellos, comprender que al hablar de los jugadores hay controversias sobre la necesidad de masculinización para que las chicas sean reconocidas en el fútbol.

Palabras clave: Mujeres, Fútbol, Cultura, Gén 
Endereço para correspondência:

Tadeu João Ribeiro Baptista

E-mail: tadeujrbaptista@yahoo.com.br 